\title{
Impact of the JOBS Intervention on Unemployed Workers Varying in Risk for Depression $^{1}$
}

\author{
Amiram D. Vinokur ${ }^{2}$ and Richard H. Price \\ Institute for Social Research, University of Michigan \\ Yaacov Schul \\ Hebrew University of Jerusalem
}

Reports the results of the JOBS II randomized field experiment that included a sample of 1,801 recent job losers, 671 of which participated in a modified version of the JOBS I intervention for unemployed workers (Caplan, Vinokur, Price, \& van Ryn, 1989). The intervention focused on enhancing the sense of mastery through the acquisition of job-search and problem-solving skills, and on inoculation against setbacks. JOBS II was intended to prevent poor mental health and to promote high quality reemployment. The study tested whether the efficacy of the intervention could be increased by screening and oversampling respondents who were at higher risk for a significant increase in depressive symptoms. Results demonstrated that the intervention primarily benefited the reemployment and mental health outcomes of the high-risk respondents. This suggests the feasibility of enhancing the efficacy of this preventive intervention by tangeting it for high-risk unemployed workers who could be identified prospectively.

KEY WORDS: preventive intervention; job loss; unemployment; reemployment.

\footnotetext{
${ }^{1}$ This research was supported by National Institute of Mental Health Grant No. P50MH38330 to the Michigan Prevention Research Center (Richard H. Price, Principal Investigator).

${ }^{2}$ All correspondence should be sent to Amiram D. Vinokur, Institute for Social Research, University of Michigan, Ann Arbor, Michigan 48106-1248.
} 
A great deal of research has been conducted on the impact of job loss and unemployment on workers' stress and mental health (Barling, 1990; Fryer \& Payne, 1986; Warr, 1983). There is strong evidence showing the adverse effects of job loss and unemployment on social and psychological functioning (e.g., Catalano, 1991; Catalano \& Dooley, 1977; Dew, Bromet, \& Schulberg, 1987; Kessler, Turner, \& House, 1988, 1989; Vinokur, Caplan, \& Williams, 1987), as well as on physical health (Cobb \& Kasl, 1977) and on the family (Justice \& Duncan, 1977). During the thriving economy of the 1950s and 1960s, 4-5\% of the workforce was looking for a job (Chamberlain, Cullen, \& Lewin, 1980, p. 586). These percentages suggest that even if today's economy will once again thrive, millions of individuals will continue to be vulnerable to the harmful effects of job loss and unemployment (Reich, 1991).

Because the fundamental causes of job loss and unemployment are rooted in societal and economic processes, remedies for their adverse social effects must be sought in comprehensive economic and social policies (Blinder, 1987). Although national and state social and economic policies need to address the problems that result from unemployment, various community-based efforts can be undertaken to reduce the social and psychological impact of unemployment at the local level. For example, special community-based intervention programs can be implemented to provide support and coping skills to unemployed workers in their search for employment and to moderate the adverse effects of unemployment on mental health.

The JOBS Intervention Project developed at the University of Michigan was designed to test a preventive intervention for unemployed workers. The intervention goals were to prevent the deterioration in mental health of unemployed workers which often results from job loss and prolonged unemployment and to promote high quality reemployment. This intervention was designed as a job search seminar to teach participants the most effective strategies to find appropriate positions and to enhance their job search skills. While the seminar was aimed specifically at enhancing job search skills, it also incorporated several components designed to enhance participants self-esteem and sense of control, job search self-efficacy, and inoculation against setbacks. These components were considered essential to maintain the motivation and the persistence in job search behavior to regain employment (Caplan, Vinokur, Price, \& van Ryn, 1989). Various aspects of these components have been discussed in the literature in terms of effectance motivation (White, 1959), locus of control (Rotter, 1966), personal control (Gurin, Gurin, \& Morrison, 1978), self-efficacy (Bandura, 1977), and sense of mastery (Pearlin \& Schooler, 1978; Pearlin, Menaghan, Lieberman, \& Mullen, 1981). The intervention was originally tested in a 
large-scale, randomized experimental field study using a large heterogeneous sample of unemployed persons who were recruited from unemployment offices in southeastern Michigan (Caplan et al., 1989).

Several reports have already provided strong evidence that the intervention accomplished its goals. Using the 1-month and 4-month follow-up data, Caplan et al. (1989) showed that the intervention produced higher quality reemployment in terms of earnings and job satisfaction, and higher motivation, even among those who remained unemployed. Additional analyses on these two short-term follow-ups demonstrated that participants achieved significantly better employment outcomes and mental health than their counterparts in the control group (Vinokur, Price, \& Caplan, 1991). Finally, a long-term follow-up, $2 \frac{1}{2}$ years later, demonstrated continued beneficial effects of the intervention on wage rates, monthly earnings and fewer episodes of job changes (Vinokur, van Ryn, Gramlich, \& Price, 1991).

In later analyses of the data, we demonstrated that the beneficial mental health effects of the intervention were primarily experienced by an identifiable subgroup of respondents who were at high risk of experiencing a clinically significant setback in mental health such as experiencing a depression episode (Price, van Ryn, \& Vinokur, 1992). The high-risk respondents were those identified by higher combined scores on depressive symptoms, financial strain, and low assertiveness at pretest. Both research and theory suggest that these three variables are prominent risk factors for poor mental health and continued unemployment of persons who lose their job. Several studies demonstrated that financial strain has a significant impact on depression (Kessler, Turner, \& House, 1988). Further, depression symptoms may reduce the chances of reemployment (Hamilton, Hoffman, Broman, \& Rauma, 1993) because of their effect on the motivation for, and effectiveness of, job search behavior. Finally, lack of assertiveness and associated social skills hinders effective interpersonal communication with potential employers and therefore reduces the chance of landing a job.

Despite the positive results obtained in the testing of the JOBS intervention, a number of questions are yet to be answered. One question is whether the retrospective identification of this subgroup could be translated into a prospective screening mechanism to increase the effectiveness of an intervention program aimed at preventing poor mental health outcomes. Furthermore, while risk status was defined and demonstrated to be an important predictor of the intervention effect on mental health, it remains to be seen whether risk status also moderates the effect of the intervention on reemployment outcomes. Recent studies implicate the increase in depressive symptomatology that follows a job loss as contributing to continuation of unemployment status (Hamilton et al., 1993). However, if the JOBS intervention is more effective in reducing depressive symptoma- 
tology among high- than low-risk respondents, it may also be more effective in improving the reemployment outcomes of the high- than the low-risk respondents by shortening their period of unemployment. That is, we hypothesize that the intervention will produce greater reemployment benefits for the high-risk individuals than the low-risk ones, as had been demonstrated with respect to mental health.

A number of prevention researchers and theorists have enumerated the advantages of maximizing the effects of interventions on mental health through the identification of mediating variables and the screening and targeting of the intervention on the mediators (Brown, 1991; Emery, 1991; Pillow, Sandler, Braver, Wolchik, \& Gersten, 1991; Reid, 1991). ${ }^{3}$ We hypothesized that advanced screening of high-risk job losers and their selection into the JOBS intervention could increase the efficacy of the intervention since it would include those job losers who could benefit most from the intervention.

The purpose of this paper is to report the results of the JOBS II study, a large-scale extension of the original randomized field experiment using the JOBS intervention. The most important extension in this JOBS II study included the testing of a screening instrument and a procedure to identify, oversample, and recruit high-risk job losers, and then to randomize the high- and low-risk respondents into the intervention and a control condition. Another extension of the original study included the collection of data from a spouse or another significant other who knew the respondent well and could report on his or her mental health and role and emotional functioning. These additional reports by significant others could provide convergent validation of the respondents' report of their own mental health and role and emotional functioning and shed additional light on the interpretation of the results.

Apart from these extensions of the original study, the present JOBS II study was intended to provide an operational replication (Lykken, 1968) of the original study. Thus, the main basic features of the earlier study and the intervention, such as the sources and procedures for recruiting respondents, and for the delivery of the intervention, including its content, remained essentially the same. However, the new study included a number of important changes as well.

\footnotetext{
${ }^{3}$ Risk factors may include early epidemiological risk factors such as demographics as well as mediational variables involved in the process producing the problem that is intended to be prevented. For example, Pillow et al. (1991) suggest that interventions to prevent poor mental health of children of divorce should use screening on the mediating variables that include parental conflict and lack of parental warmth and support for the children. Similarly, interventions to prevent poor mental health of job losers, such as the JOBS II intervention, may include financial strain, which has been demonstrated to mediate the effects of job loss on depression symptomatology (Kessler et al., 1987; Pearlin et al., 1981).
} 
First, the conceptual framework that guided the JOBS II intervention focused on increasing the sense of mastery and the enhancement of personal control and job search self-efficacy. The importance of increasing the focus on sense of mastery and control has been highlighted by new research on these constructs in our earlier study and in research by others. For example, research findings from the JOBS I study demonstrated that increases in job-search self-efficacy had a significant impact on the intensity of job search behavior (van Ryn \& Vinokur, 1992). In a similar vein, Eden and Aviram (1993) tested a similar intervention for job losers and demonstrated that their intervention increased general self-efficacy and job search behavior. More generally, enhancing a sense of mastery appears to be an essential step in reducing the risk for depression. For example, Marshall and Lang (1990) have demonstrated that mastery-and not optimism-was the critical predictor of depression among the women in their sample.

Second, changes were introduced to increase the strength, integrity, and efficiency of the intervention. The new JOBS II study included the hiring of a new team of six cotrainers and increasing their formal training from 80 to 240 hours. To increase efficiency and attendance, the intervention was shortened from eight sessions during a 2-week period (in JOBS I) to five sessions during a 1-week period (in JOBS II) with total number of intervention hours reduced by $30 \%$ (approximately from 28 to 20 hours).

Third, perhaps the most significant change in this extension of the original study occurred in the economic environment during and immediately after the time of the intervention, when the participants were searching for a new job. Whereas data from the U.S. Bureau of Labor Statistics $(1988,1992)$ indicate that the conditions of the labor market for job seekers became much better during the year following the original JOBS I intervention, these conditions became much worse during the year following the replication JOBS II intervention study. Thus, if the JOBS II study also replicates the beneficial effects demonstrated by the original study, it would lend a strong support to the robustness and efficacy of the JOBS program using a new set of trainers and supervisory personnel, and most important, demonstrating results under different, more difficult, conditions of labor market trajectory. Such findings would suggest the suitability and practicality of implementing this program in various community settings undergoing expansions or contractions in their labor markets. Because of these changes, the findings of the JOBS II study provide additional implications regarding the generalizability of the intervention to other settings and the nature of the economic environment.

To summarize, the goals of this paper are to examine the following four questions: (a) Was the redesigned JOBS II intervention aimed at enhancing participants' sense of mastery successful in achieving this outcome? 
(b) Did the intervention replicate the positive effects on reemployment and mental health outcomes obtained in JOBS I, particularly with a procedural variation that shortened the intervention, and delivered it in a different economic environment? (c) Having used a new prospective design for screening high-risk respondents, did the intervention replicate the JOBS I findings showing that the high-risk participants benefited most in terms of reduction in depression symptoms? (d) Did the findings regarding the differential positive effects of JOBS II for high-risk participants generalize to other measures of well-being, such as distress and role and emotional functioning as reported by both participants and their significant others?

\section{METHOD}

\section{Subjects and Overview of the Design}

An overview of the design of the study including the steps involved in screening and recruitment, and in pretest, and posttest data collections is displayed in Fig. 1.

\section{Method and Procedures of Recruitment}

Respondents were recruited from four offices of the Michigan Employment Security Commission (MESC) in southeastern Michigan, the state agency that provides unemployment payments. Trained interviewers approached and contacted 31,560 potential respondents while they waited in the unemployment offices and briefly inquired whether they were unemployed and were looking for a job. Over 23,000 of those contacted were ineligible for participation because they were new entrants to the labor market, already reemployed, or were just accompanying others in line. Thus, of those contacted, only 7,956 (Fig. 1, Box 2) met basic initial criteria, which also included information from the respondents that they were not on strike or expecting to be recalled for work in the next few months, or planning to retire in the next 2 years. Those who met all of the above initial criteria were asked to fill out a 5-page, self-administered screening questionnaire described below to determine three additional final eligibility criteria and to provide baseline pretest measures. Only 3,402 (Fig. 1, Box 3) met all eligibility criteria for participation in the field experiment. Of the three final exclusion criteria, the first included information that the respondent had lost his/her job and was unemployed for over 13 weeks. The second criterion was designed to exclude respondents who were likely to introduce 


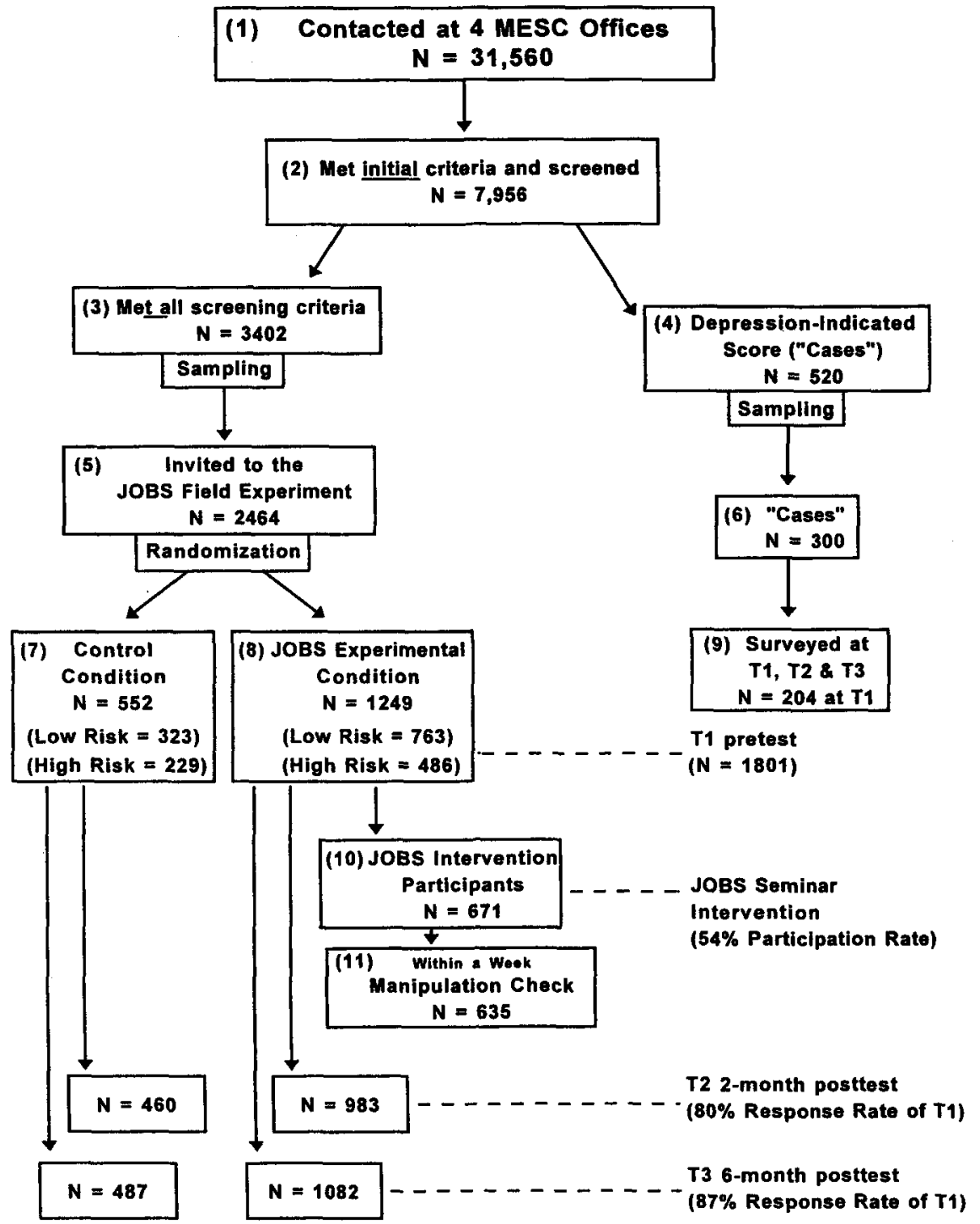

Fig. 1. Research design of the JOBS II Field Study.

selection and attrition bias due to a strong preference for the program offered to the control or the experimental group. Thus the respondents were told about two programs that were being offered by the University of 
Michigan on how to seek jobs. One program was described as a five halfday (Monday through Friday) seminar series (the experimental condition); the other was described as a self-guided booklet program (the control condition). To ensure equal motivation to enter one or the other condition, only persons who expressed no preference were randomly assigned to the experimental and control conditions. Of the 7,956 selected initially, those $1,159(14.6 \%)$ who expressed a preference for one of the programs (versus having no preference) and the 108 respondents who refused both programs (1.3\%) were excluded from the study but were sent the job search booklet and eliminated from the sample. The majority of those with a preference preferred the self-administered program.

The third criterion was designed to exclude those with a very high depression score indicative of a depression episode (Derogatis \& Melisaratos, 1983) because the intervention was conceived of as a primary prevention program. Those $520(6.5 \%)$ respondents who were excluded based on this criterion were not included in the design of the experiment. ${ }^{4}$

The screening questionnaire requested information on each respondent's name, address, telephone number, birth date, gender, and nי..' of weeks unemployed since leaving last job. It also included index of depression symptoms, a 3-item index of financial strain, and a 4-item index of social assertiveness. Based on the scores for the three indices, and using the regression weights reported in Price et al. (1992), a risk score for poor mental health was computed for each respondent. In addition, a risk status code (i.e., low $=1$, high $=2$ ) was assigned to each respondent based on the risk score. (For details on risk score and risk status see section on measures.) Of the 3,402 that met all of the criteria of eligibility (Fig. 1, Box 3), 2,445 (72\%) were classified as low risk but only 1,507 were invited (randomly selected) to participate in the study. Reducing the proportion of low-risk respondents was the method used to achieve oversampling of the high-risk respondents from 25 to $39 \%$.

\footnotetext{
${ }^{4}$ Although those with very high depression scores were not included in the design of the study, a random panel of 300 of the 520 with high depressive scores were selected to be followed up with our questionnaire surveys. However, all of the 520 respondents who had very high depressive symptoms were mailed our job search booklet. In addition, because they were more likely to experience a clinically significant depressive episode, we included in the material that we sent to them a community resource guide for mental health and welfare services that included addresses and phone numbers of mental health clinics and related social agencies and institutions where treatment and help can be obtained. Prior to composing the informational guide, we contacted all of the social agencies and clinics who appear on the guide to inform them about our action, and to solicit and obtain their cooperation in providing the needed help to those who would call. Having this informational guide available, we included it with the package of questionnaires that was mailed to all other respondents in the study with an accompanying letter that explained the general purpose of having this information for unemployed persons.
} 


\section{Randomization Procedures and Experimental Design}

Each week, interviewers screened and recruited respondents at two of the four MESC offices mentioned above. Screening questionnaires were brought to the research office to complete the scoring of scales and determine risk status and eligibility. Subsequently, a computerized randomization procedure was used to allocate the low- and the high-risk respondents to a control condition or an experimental condition. Those randomized to the experimental condition received an invitation to participate in the JOBS intervention program in a site chosen for its proximity to the office from which they were recruited.

\section{Experimental Condition}

The JOBS seminar experimental condition consisted of five 4-hour sessions conducted during the morning hours of a 1-week period. All persons in the experimental condition were mailed an invitation to attend the seminar with a $\$ 5$ bill incentive to cover transportation costs. Respondents assigned to the experimental condition were also told that they would receive a $\$ 20$ check payment for completing at least 4 of the 5 sessions and a certificate of participation. The certificate was awarded at the last session.

Each training site was located in the geographical area in which recruitment to the site took place. The sites included community colleges, community centers, and rented conference rooms at local hotels. The rooms were large enough to accommodate 25 persons seated at movable chairs and tables. A semicircular seating layout was used to facilitate discussion, and small groups were formed to carry out group exercises.

The design of the five training sessions was based on the principles described in Caplan et al. (1989) and in Price and Vinokur (in press). They included the application of problem-solving and decision-making group processes, inoculation against setbacks, provision of social support and positive regard from the trainers, and learning and practicing job search skills. The intervention seminars were delivered by three pairs of male and female cotrainers to groups ranging from 12 to 22 participants $(M=15.6)$. The seminar trainers included social workers, educational counselors, and high school teachers who were themselves unemployed at the time but were looking for work. They were recruited and selected carefully to insure their suitability to follow the intervention protocol and facilitate group processes. They received approximately 240 hours of formal training by our staff which included conceptual knowledge of group processes, the theoretical bases of the intervention, and extensive rehearsal. The trainers also practiced by 
conducting the five session sequence twice with pilot participants. In all, the intervention was delivered to 671 participants during 22 weeks, beginning March 1, 1991 and ending August 7, 1991.

The sessions covered a wide range of substantive, skill-related topics. The topics included examples and exercises in identifying and conveying one's job-related skills, using social networks to obtain job leads, contacting potential employers, preparing job applications and resumés, and successfully going through a job interview. Each of the five sessions was standardized for the trainers in 8 to 12 pages of documentation per 4-hour session. The full details of the selection and training of the trainers' program and of the intervention are available in a comprehensive 370-page implementation manual (Curran, 1992) that can be obtained from the authors.

Intervention Quality Control. Two procedures were used to maintain a high level of trainer adherence to the protocol over the 5-month duration of the intervention. First, trainers were regularly observed by members of the research team. The observers followed a procedure worked out jointly with the trainers that allowed for constructive feedback after the end of each observed session. Second, the trainers met weekly with a staff person in charge of their training to deal with special skill-related topics that surfaced in their work as trainers.

Intervention Dropouts and Participants. Among those who were assigned to the experimental condition and became study participants by returning the Time 1 (T1) pretest questionnaire (Fig. 1, Box $8 ; n=1,249$ ), $46 \%(n=578)$ failed to show up for the intervention but continued to provide follow-up data at Time 2 (T2) and Time 3 (T3). Of those 671 who showed up (Fig. 1, Box 10), 567, or $85 \%$, showed up for at least four of the five sessions. Most of the participants who attended the beginning sessions but dropped out of the later ones indicated they had found a job during the week of the seminar.

\section{Control Condition}

The control condition consisted of a booklet briefly describing jobsearch methods and tips equivalent to three single-spaced pages of text. This booklet was mailed to persons after they were randomized into the control condition. The booklet contained useful information, but it was extremely brief in comparison, for example, to self-help books available on job search. 


\section{Data Collection Procedures}

After completing the screening questionnaire at an MESC office, the questionnaire was processed and a risk score was calculated. Those who were eligible for participation and who were randomized into one of the experimental conditions were mailed a package including a questionnaire for themselves and a separate questionnaire for their significant other. The package included separate self-addressed stamped envelopes for returning the questionnaires, a $\$ 5$ bill attached to each questionnaire, an introductory letter to the respondent and to the significant other. An enclosed cover letter described our guarantee of confidentiality, a certificate of confidentiality obtained from the federal government, and an assurance that the study was not connected with MESC.

Significant Other was defined as the spouse of the respondent if he/she was married and living with the spouse, or else someone to whom the respondent feels close to, who knows the respondent well and sees the respondent at least once a week.

$\mathrm{T} 1$ pretest questionnaires were mailed weekly to cohorts of respondents who were recruited to the study during the months of February through July 1991 . The questionnaires were mailed about 2 weeks before the invitation for the JOBS intervention seminar to which the respondents were randomized as experimental or control respondents. Based on the respondents' reports, it took an average of 44 minutes to complete the T1 pretest questionnaire.

Program evaluation questionnaires were mailed to the respondents immediately after they completed the intervention seminar with a separate envelope to update their address so they could receive the $\$ 20$ payment for participation.

On the average, two of the five sessions of each seminar group were observed by a project staff member such as the training supervisor, project directors, and assistants, and by two of the trainers who were on a rotating schedule of research assignment every third week.

$\mathrm{T} 2$ and $\mathrm{T} 3$ follow-up questionnaires were mailed to the respondents 2 and 6 months, respectively, after the week of the intervention seminar for which they were randomized as experimental or control respondents. In addition to the $\$ 5$ bill that was included with these follow-up questionnaires, respondents who did not return the questionnaires within 4 weeks were sent an offer of a $\$ 12$ bonus to be paid by check upon receiving their completed questionnaires. This latter incentive method, which started in the middle of Wave 2 follow-up, resulted in a substantial increase in response rate (about 14\%) and accounts for the higher T3 than T2 response rate. 


\section{Measures}

All of the constructs in this study were assessed with multi-item indices, and most had a coefficient alpha in the .70s and $.80 \mathrm{~s}$. Below we present that subset of measures that were used for the analyses of this report. The full set of measures and the questionnaires are available from the authors.

Demographics were assessed using standard survey questions for reporting age, sex, education, marital status, occupation, family income, and ethnic/racial identification.

Depression was measured with a subscale of 11 items based on the Hopkins Symptom Checklist (Derogatis, Lipman, Rickles, Uhlenuth, \& Covi, 1974). The 11-item scale required respondents to indicate on a 5point scale how much $(1=$ not at all to $5=$ extremely $)$ they had been bothered or distressed in the last 2 weeks by various depression symptoms such as feeling blue, having thoughts of ending one's life, and crying easily. The Cronbach coefficient alpha (Nunnally, 1978) of the scale was .90.

Financial strain was measured with a 3-item index (Kessler et al., 1988; Vinokur \& Caplan, 1987) based on answers to three questions with 5-point rating scales. The questions asked: "How difficult is it for you to live on your total household income right now?"; "In the next two months, how much do you anticipate that you or your family will experience actual hardships such as inadequate housing, food, or medical attention?"; and "In the next two months, how much do you anticipate having to reduce your standard of living to the bare necessities of life?" The alpha coefficients for the index ranged for the three data collection waves from .84 to .90 .

Assertiveness was assessed using a short 4-item index $(\alpha=.85)$ based on published instruments on social reticence and shyness (Jones \& Russell, 1982) and assertiveness (Galassi, Delo, Galassi, \& Bastien, 1974; Rathus, 1973). The 4-item scale required respondents to indicate how strongly they agreed or disagreed $(1=$ strongly agree to $5=$ strongly disagree $)$ with various statements about themselves, such as "I feel inhibited in social situations," and "Most people seem to be more aggressive and assertive than I am."

Risk Score and Risk Status. A Risk score index was computed based on the screening data according to the following formula developed in Price et al. (1992): Risk score $=(.622 *$ Depression score $)+(.134 *$ Financial Strain score $)-\left(.098^{*}\right.$ Assertiveness score $)$. The regression weights suggest that respondents who score higher on depression symptoms and financial strain and lower on assertiveness are at higher risk for experiencing depression in the future. Before classifying respondents into low- and high-risk status categories we excluded all $520(6.5 \%)$ respondents (Fig. 1, 
Box 4) who had a mean depression index greater than 3.00 , which is considered a clinically significant indication of depression (Derogatis \& Melisaratos, 1983). As already indicated, these respondents were not included in the design of the field experiment because the intervention was conceived of as a primary prevention program. Thus, to be classified in the high-risk category, respondents had to have a risk score greater than or equal to 1.38. Respondents who had a risk score less than 1.38 were classified in the low-risk status category. The 1.38 cutting point was set to obtain approximately $25 \%$ high-risk respondents before oversampling, as in Price et al. (1992). ${ }^{5}$

Distress symptoms were measured with an 18-item index assessing a variety of distress symptoms such as restlessness, anxiety, and inattentiveness. The items required the respondents to indicate on 5-point scales "how much of the time during the last two weeks have you been . .." experiencing the various symptoms. The scales range from 1 (none of the time) to 5 (all of the time). Using the same items, the spouse/significant other reported their assessment of how the focal respondent has been during the last 2 weeks. The Cronbach alpha for the focal respondent's measure was .95. For the significant other's measure assessing the focal respondent's depression symptoms the alpha coefficient was .93 .

Role and emotional functioning was measured with a 15 -item index developed by Caplan et al. (1984). The items require the respondents to indicate "how well have you been doing (in the last two weeks) with respect to ..." various role and emotional tasks such as handling responsibilities and daily demands, staying level-headed, and making the right decisions on a 5-point scale $(1=$ very poorly, $5=$ exceptionally well). Using the same items, the respondent's spouse/significant other also reported on the role and emotional functioning of the focal respondent. The Cronbach al-

\footnotetext{
${ }^{5}$ In addition to the risk score that was computed based on Price et al., 1992 study, we also computed a new risk score based on the data from the current study. Using the new score, we then conducted the analyses reported in the result section again. Despite some differences in the weights of the components of the old and new risk score, the results obtained using the two risk scores were the same. The two risk scores correlate .99 . Furthermore, $97 \%$ of the respondents are classified into the high- or low-risk categories by either the old or the new score. Additional analyses were conducted based on two new cutting points that classify, respectively, 50 and $75 \%$ of the respondents as high risk. The results based on the currently used cutting points that classify after oversampling only $40 \%$ of the study participants as high risk were the strongest. Although not statistically significant, the results with $50 \%$ classified as high risk, were close to those based on the current cutting point. Income per month was the only outcome where the cutting point based on $50 \%$ high risk was slightly but not significantly stronger than the one based on the currently used cutting point. Thus, our cutting point for classifying high-risk respondents seems optimal for identifying a subgroup that benefits most from the intervention.
} 
pha for the focal respondent and the significant other measure was .94 and .95 , respectively.

The job search self-efficacy measure was developed for this study and consisted of 6 items. All respondents, regardless of reemployment status, were asked to rate how confident they felt about being able to do the following things successfully: make the best impression and get points across in an interview, contact and persuade employers to consider them for the job, complete a good job application or resumé, use friends or other contacts to discover promising job openings, use friends and other contacts to find out about employers that need their skills, and make a good list of all the skills they have which could be used to find a job. The rating scale categories ranged from 1 (not at all confident) to 5 (a great deal confident). Ratings on these items were averaged to create a job search self-efficacy index measure with a Cronbach's alpha coefficient of 87 .

The self-esteem measure included 8 items from Rosenberg's (1965) self-esteem scale. The items requested the respondents to rate their degree of agreement or disagreement with statements such as "On the whole I am satisfied with myself," "I am able to do things as well as most other people," "At times I think I am no good at all." The categories for the rating scales ranged from 1 (strongly agree) to 5 (strongly disagree). This 8-item measure had a Cronbach alpha coefficient of .83.

An internal control orientation measure was based on 10 items from the original Rotter I-E scale that were demonstrated by Gurin et al. (1978) to best capture a personal, rather than ideological, orientation. The items of this scale are very similar to those used in another widely used SelfMastery scale (Pearlin \& Schooler, 1978; Pearlin et al., 1981). Alpha coefficients of this measure ranged from .63 to .71 across the time waves.

The mastery measure was constructed by computing the mean scores of the above three measures (i.e., jobs search self-efficacy, internal control orientation, and self-esteem). This combined measure was constructed following a confirmatory factor analysis that tested whether the three constructs could be accounted for by a latent factor conceived of as personal mastery. Analysis using structural equation modeling (Bentler, 1989) provided a very good fit to the model as measured by several fit indexes including Bentler and Bonnett (1980) normed, nonnormed, and comparative fit measures (NFI $=.98, \mathrm{NNFI}=.97, \mathrm{CFI}=.98$, respectively) and Hoelter's (1983) $\mathrm{CN}=759$.

Intervention Process. Assessments of the participants' immediate perception of the process within the intervention provided an indication of the intervention's integrity and strength (Yeaton \& Sechrest, 1981). These assessments were based on measures that consisted of multi-item indices and covered various aspects of the intervention such as trainers' and group 
members' behavior, their attractiveness to the participant, social processes (e.g., freedom to participate, willingness of the group to listen to what one had to say); and practice of job-seeking skills within the sessions. It also included measures of the proximal impact of the intervention on job search self-efficacy, job search optimism, and confidence in being able to handle setbacks and self-esteem.

Reemployment. Following the definition used in our earlier JOBS I study (Caplan et al., 1989), reemployment status was determined by a combination of two criteria. To be classified as "reemployed" the person had to report working at least 20 hours per week and had to characterize the number of hours being employed as "working enough." Persons working less than 20 hours per week and characterizing that amount "not working enough" were classified as "not reemployed." Persons who did not clearly fall into either of these categories (28\% at $\mathrm{T} 2$ and $22 \%$ at T3) were omitted from analyses that include the reemployment measure. This operational definition provides an unambiguous characterization since the person is coded as employed only when meeting both subjective and objective criteria. To avoid the omission of a middle subgroup that occurred in the application of the above definition, we also used another definition of reemployment status that included all the respondents. This definition was based solely on the reported number of work hours per week. Those working less than 20 hours per week and those working for 20 hours or more were classified, respectively, as unemployed and reemployed. In addition to reporting the number of hours working per week, respondents also provided information on their wages from which we calculated their wage rate and monthly income.

\section{Demographic Characteristics of the Sample of Respondents Enrolled in the Study}

Our study's sample, which included those who were enrolled by returning the T1 pretest questionnaire (Fig. 1, Boxes 7, 8, and 9, $N=2,005$ ), was composed of workers who had lost a job recently and were unemployed for no longer than 13 weeks. Nevertheless, its characteristics closely resembled the U.S. unemployed population as reported by the U.S. Bureau of Labor Statistics (1992), which also include long-term unemployed, and reentrant and new entrants to the labor market. For example, in our sample, the median age was 34.7 years $(M=36.20, S D=10.38)$; and included $45 \%$ male, $21.5 \%$ African American, $76 \%$ white, $41 \%$ married, and a mean of $\$ 1,881$ monthly income from last job. The U.S. unemployed population dur- 
ing 1991 had a median age of 30.4 years; and included 58\% male, 20\% African American, $76 \%$ white, $41 \%$ married and monthly earnings of $\$ 1,834$.

In our sample, only $8.6 \%$ did not complete high school, $32.4 \%$ had high school education, $35.8 \%$ had some college, $13 \%$ had 4 years of college, and $10.2 \%$ had more than 4 years of college. Respondents were recruited to the study between 1 and 13 weeks following their job loss $(M=4.11$; $S D=3.8)$. On the average, they had worked 3.85 years $(S D=5.01)$ on their last job, 43.21 hours per week $(S D=9.52)$, and earned $\$ 10.01(S D$ $=4.86)$ per hour. Their mean annual income was $\$ 22,574(\mathrm{SD}=\$ 11,932)$.

\section{Response Rates, Attrition, and Effectiveness of Randomization}

Attrition from TO (Screening) to T1

Of those 2,464 who were selected, randomized and invited to participate in the field study based on their T0 (screening) data (Fig. 1, Box 5), 1,801 respondents $(73 \%)$ were enrolled by returning their $\mathrm{T} 1$ questionnaire (Fig. 1, Boxes 7 and 8) . Our analyses revealed that males, younger respondents, and those experiencing higher levels of financial strain were significantly more likely to drop out of the study by not returning the $\mathrm{T} 1$ questionnaire. However, there were no differences in attrition rates between the experimental and control condition or between low- and high-risk groups that formed our experimental design. Moreover, there were no interactions between attrition and experimental conditions on any of the variables available in the screening data including age, gender, number of weeks since job loss, depression, financial strain, and assertiveness, or the risk score (the combination of the latter 3 measures).

\section{Attrition from $T 1$ to $T 2$ and $T 3$}

Of those 1,801 who enrolled in the study, $1,443(80 \%)$ provided $\mathrm{T} 2$ and $1,569(87 \%)$ provided T3 questionnaires. We also received from their significant others at $\mathrm{T} 1, \mathrm{~T} 2$, and $\mathrm{T} 31,483(82 \%), 1,304(90 \%)$, and 1,466 (92\%) questionnaires, respectively. The higher response rate at $\mathrm{T} 3$ than at $\mathrm{T} 2$ was the result of additional follow-up contacts and higher respondent pay.

There was no significant difference in attrition between experimental and control condition nor any significant interactions between experimental conditions and risk status, consequently, the integrity of the randomization to experimental and control conditions was fully preserved (Hansen, Collins, Malotte, Johnson, \& Fielding, 1985). There were no significant 
differences in any of the $\mathrm{T} 1$ variables between respondents randomized to the experimental and control conditions, nor an interaction between condition and risk status, nor between condition and any of the individual components of the risk status index, that is, depression, financial strain, and assertiveness. In addition, none of the $\mathrm{T} 1$ demographics or job-related variables including age, sex, education, family income, number of dependents, number of hours worked per week on last job, and wage rate on last job was associated with experimental condition.

Compared to respondents who provided data for the T2 follow-up, dropouts were significantly older (37.00 vs. 32.85 years, $p<.001)$, male (vs. female) 51 vs. $44 \% ; p<.01$ ), nonwhites (33 vs. $21 \% ; p<.001$ ). They also had less education (13.16 vs. 13.60 years, $p<.001$ ), lower family income $(\$ 22,169$ vs. $\$ 27,955 ; p<.001)$ and lower prior monthly income from the job they lost $(\$ 1757$ vs. $\$ 1911, p<.01)$ and experienced higher financial strain (3.31 vs. $3.13, p<.01)$ than those who responded. There was also a statistically significant difference in the proportion of dropouts between the experimental and control condition at $\mathrm{T} 2(16.7 \%$ dropout in the control vs. $21.3 \%$ dropout in the experimental condition, $p<.02$ ). However, with more intensive follow-up at $\mathrm{T} 3$, the dropout difference was reduced to a nonsignificant $1.6 \%$ between the control and experimental conditions. Most important, we tested for interaction effects between dropout and experimental condition on 17 variables that included demographics and screening and pretest scores on mental health and job related variables (e.g., prior monthly income). No statistically significant interaction effect was found for either Time 2 or Time 3 dropout. Following Hansen et al. (1985) we conclude that differential attrition rates could not affect the internal validity of the results.

\section{RESULTS}

\section{Manipulation Checks on the Integrity and Strength of the Intervention}

Of those 1249 job seekers who were assigned to the experimental condition and were invited to the job search seminar, 671 (54\%) participated in the intervention. Of these 671 participants, $85 \%$ attended at least 4 of the 5 sessions. Thus, the mean number of sessions attended was 4.27. Using a mailed self-administered questionnaire, 635 (95\%) of those who attended the intervention seminar reported their evaluation and experiences within a week after the last session. Their evaluations provided uniformly strong evidence of the integrity and strength of the intervention and its immediate impact. On a series of 5-point scales ranging from 1 to 
5 , participants provided ratings indicating that they found the seminar relevant to their needs $(M=4.51, S D=0.46)$, that the group process was highly positive $(M=4.59, S D=0.43)$, and that their job-search optimism and their confidence in overcoming setbacks was high $(M=4.40,4.15 ; S D$ $=.52, .68$, respectively). They also rated the trainers and their fellow group members on warmth, expertise, and helpfulness on 7-point scales ranging from 1 to 7. Again, these ratings indicated positive evaluations with mean scores of $6.77(S D=0.63)$ and $6.73(S D=0.69)$, respectively.

Finally, comparison of measures that were available at pretest $\mathrm{T} 1$ with the same measures collected within a week after the intervention seminar demonstrated sizable increases in self-esteem $(M s=4.40$ vs. 4.09$), t(631)$ $=12.86, p<.001$, Cohen's effect size $d=.51$, job-search self efficacy $(M \mathrm{~s}$ $=4.37$ vs. 3.61$), t(631)=22.91, p<.001, d=1.27$, and confidence in being prepared to handle setbacks $(M s=4.11$ vs. 3.54$), t(631)=17.02, p$ $<.001, d=.86$. These findings suggest that the intervention provided the participants with the intended positive and socially supportive group process as well as raising self-esteem, job search self-efficacy, and inoculation against setbacks.

\section{Analyses of the Experimental Effects of the Intervention}

\section{Analysis Plan}

To preserve the integrity of the randomized design and avoid selection bias (Cook \& Campbell, 1979), our analyses include in the experimental group all the respondents who were randomized to this group regardless of whether they subsequently showed up and participated in the intervention seminar. The analyses apply the General Linear Model procedure (see Cohen \& Cohen, 1983) that explores the influence of three independent variables on the different outcomes. Two of the independent variables were between-subjects factors: Condition (Experimental vs. Control) and a quantitative factor, that is, the respondent's risk score. The third independent variable was a within-subject factor, namely, time of data collection (when available pretest at screening or $\mathrm{T} 1$, and at $\mathrm{T} 2$ and $\mathrm{T} 3$ posttests). Because respondents were randomized to the experimental conditions by site, site was also used in additional analyses as an independent factor, in addition to experimental condition, risk status, and time. However, the results of these analyses demonstrated that site had no main effect or interactive effects with the other independent variables on our outcomes. Furthermore, since the results of the analyses that excluded site as a factor were virtually the same as when site was included, and to avoid unnecessary 
complexity, we present the analyses that do not include the site as a factor. Similarly, the possible main and interactive effects of other factors on the dependent variables such as that of characteristics of the pair of trainers and the period of year (trainers increased experience as they trained more groups) were also tested. There were no significant main or interactive effects with risk and condition of these variables on the outcomes. These variables are therefore not included in the remaining analyses.

The pattern of differences and interactions between low- and highrisk participants and experimental conditions are displayed in figures for dependent measures that are based on indices (e.g., mastery, depression), and in tables for dependent variables that are based on interpretable natural units (e.g., reemployment status, income per month). In these figures and tables, the data are presented according to risk status in terms of lowand high-risk categories as defined prospectively and used for randomizing respondents into the experimental and control condition. The same ANOVAs were repeated using risk as a factor with low- and high-risk levels (risk status) based on our screening categorization. These analyses produced virtually the same results as those using the continuous risk score. This absence of difference provides justification for presenting the results in the figures and tables according to our prospective categorization of lowand high-risk status. The analyses of the experimental effects of the intervention are presented first on the sense of mastery, and then on the intended reemployment and mental health outcomes. Finally, we present analyses for examining the convergent validity of the intervention effects based on reports of both job seekers and their significant others. The matrix of the intercorrelations among the experimental and the dependent variables at Times 2 and 3 posttests is presented in Table $I$.

\section{Effects on Mastery as a Proximal Outcome.}

The JOBS II intervention was redesigned to focus on the enhancement of sense of personal mastery through addressing both the emotional and problem-solving coping tasks of the jobs seeker. We hypothesized that this intervention focus would therefore have a beneficial impact on this construct.

We then analyzed the mastery index ${ }^{6}$ as a function of Condition (Experimental vs. Control), respondent's Risk Score, and Time of measurement (Table II). The results of this analysis are displayed in standardized $z$-score units in Fig. 2.

${ }^{6}$ The same analysis was performed separately on each component of the mastery measure and the pattern of the results was the same as that for the global mastery measure. 


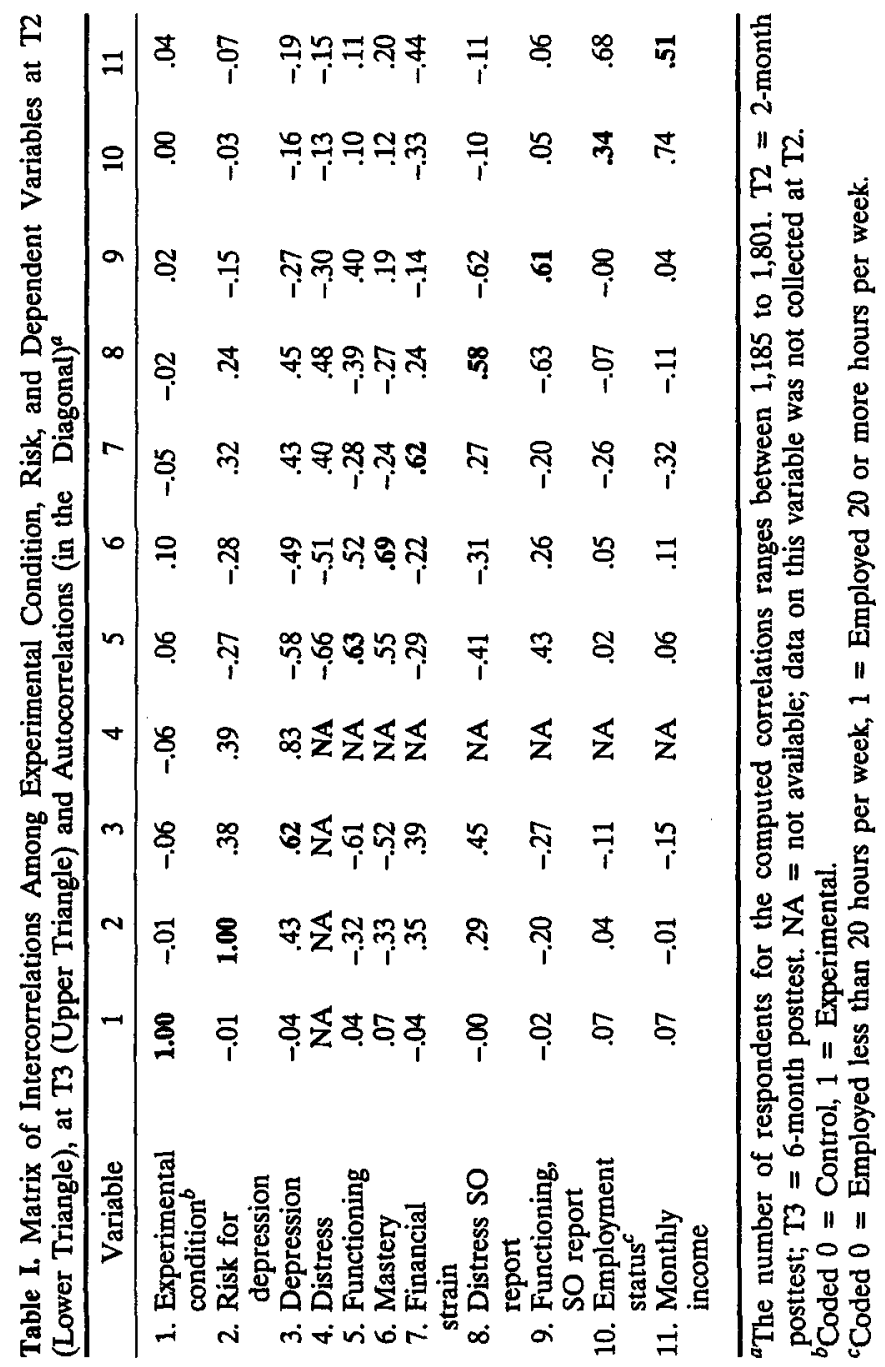


Table II. Summary Table of General Linear Model procedure of ANOVA for Mastery

\begin{tabular}{lrcrr}
\hline \multicolumn{1}{c}{ Source } & $d f$ & $S S$ & $M S$ & $F$ \\
\hline & \multicolumn{5}{c}{ Between subjects } \\
Condition (C) & 1 & 2.25 & 2.25 & $4.47^{a}$ \\
Risk & 1 & 103.4 & 103.4 & $204.86^{b}$ \\
$\mathrm{R} \times \mathrm{C}$ & 1 & 0.82 & 0.82 & 1.64 \\
Error & 1332 & 669.97 & 0.50 & \\
& & & & \\
Time (T) & 2 & 19.31 & 9.65 & $110.87^{b}$ \\
$\mathrm{~T} \times \mathrm{C}$ & 2 & 3.56 & 1.78 & $20.43^{b}$ \\
$\mathrm{~T} \times \mathrm{R}$ & 2 & 1.83 & 0.92 & $10.53^{b}$ \\
$\mathrm{~T} \times \mathrm{R} \times \mathrm{C}$ & 2 & 0.03 & 0.02 & 0.19 \\
Error (Time) & 2664 & 231.97 & 0.09 & \\
\hline$a_{p}<.05$. & & & \\
$b_{p}<.01$. & & &
\end{tabular}

The results show that although prior to the intervention there was virtually no difference on level of mastery between the experimental and the control group, after the intervention the experimental group had higher mastery scores than the control group (for Time 2 and Time 3: Cohen's $d$ $=.19$ and .21 , respectively). The analysis produced statistically significant Condition main effect, and a Condition $\times$ Time interaction effect (respectively, $p<.05, p<.01$ ). As expected, the high-risk respondents had significantly lower mastery scores than the low-risk respondents $(p<.01)$. However, risk did not moderate the effect of the intervention on mastery. Thus, although we expected the JOBS intervention to result in a greater increase in sense of mastery for the high- rather than the low-risk participants, it produced the same increase for both types of participants. Next we turn to the question of whether the intent of the intervention to improve the reemployment outcomes of the participants materialized.

\section{Experimental Effects on Reemployment Outcomes.}

Our first analysis of employment outcomes focused on rates of reemployment at $\mathrm{T} 2$ and $\mathrm{T} 3$. We performed separate analyses in which reemployment was defined either in terms of a combination of the objective 


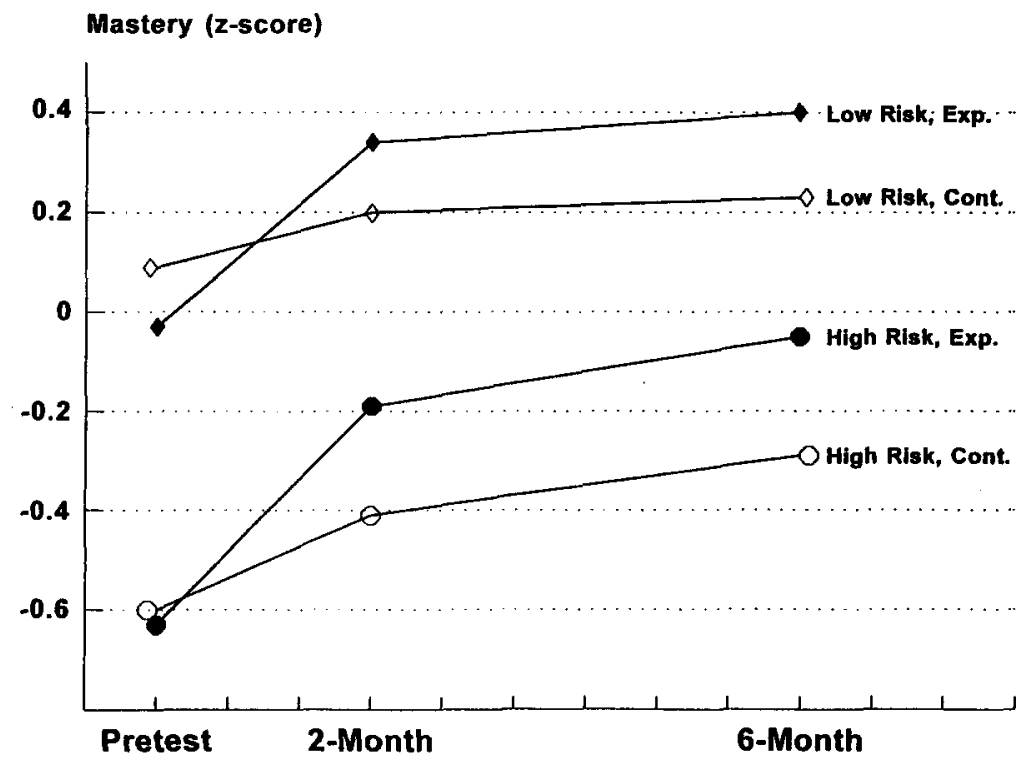

Fig. 2. Mean $z$ scores of mastery for low- and high-risk respondents in the experimental and control conditions of the JOBS field experiment.

and subjective criteria, or solely in terms of an objective criterion of working 20 or more hours per week.

Since both versions of the dependent variables were defined as a dichotomous variable (reemployed vs. unemployed status) logistic regression was used to analyze reemployment outcomes (Neter \& Wasserman, 1974). As in the previous analyses, we examined the effects of experimental condition, the continuous risk measure, and their interaction on the dependent variable. Table III presents the proportion of reemployed respondents in each of the four combinations of experimental condition and risk status at the 2-month and 6-month posttests. The top and the bottom of Table III present the results according to the reemployment measure based first on the combined measure and second on the objective measure. At 2-month posttest, a higher proportion of both low- and high-risk respondents in the experimental group than in the control group was reemployed, Wald's $\chi^{2}(1)$ $=4.44$ and 5.79 , for combined and objective criterion, respectively, both $p$ $<.05$. There was no interaction between experimental condition and risk. In contrast, by the 6-month posttest, the likelihood of reemployment depended jointly on the condition and risk factors, as indicated by a significant Condition $\times$ Risk interaction, Wald's $\chi^{2}(1)=4.13$ and 4.55 , for combined 
and objective criterion, respectively, both $p<.05$. The nature of this interaction can be noted in the results showing that the likelihood of reemployment of low-risk respondents in the intervention group was not significantly different than that in the control group $(p=.44)$. However, high-risk respondents in the intervention group were significantly more likely to be reemployed than high-risk controls $(p<.05)$. The difference in the proportion of reemployed respondents between experimental and control conditions for the low-risk group was -.03 (proportions of .59 vs. 62 , respectively) versus a difference of .10 for the high-risk group (.56 vs. .46 , respectively, Cohen's ES $h=.20$; Cohen, 1988, pp. 180-185). The same pattern of significant results was obtained using the objective criterion for defining reemployment as presented in the bottom half of Table III. Here, the difference in the proportion of reemployed respondents between experimental and control conditions for the low-risk group was -.04 (.63 vs.

Table III. Proportion of Reemployed Respondents According to Experimental Condition and Risk Status at 2-Month and 6-Month Follow-Up Posttest

\begin{tabular}{|c|c|c|c|c|c|c|c|c|}
\hline & \multicolumn{4}{|c|}{ 2-Month posttest ${ }^{a}$} & \multicolumn{4}{|c|}{ 6-Month posttest ${ }^{b}$} \\
\hline & \multicolumn{2}{|c|}{ Experimental } & \multicolumn{2}{|c|}{ Control } & \multicolumn{2}{|c|}{ Experimental } & \multicolumn{2}{|c|}{ Control } \\
\hline & Proportion & $S D$ & Proportion & $S D$ & Proportion & $S D$ & Proportion & $S D$ \\
\hline \multicolumn{9}{|c|}{ Reemployed (combined criteria) ${ }^{c}$} \\
\hline \multicolumn{9}{|c|}{ Risk status } \\
\hline Low & .34 & .48 & .27 & .44 & .59 & .49 & .62 & .49 \\
\hline High & .35 & .47 & .29 & .45 & .56 & .50 & .46 & .50 \\
\hline \multicolumn{9}{|c|}{ Reemployed (hours per week) ${ }^{d}$} \\
\hline \multicolumn{9}{|c|}{ Risk status } \\
\hline Low & .40 & .49 & .35 & .48 & .63 & .48 & .67 & .47 \\
\hline High & .44 & .50 & .35 & .48 & .62 & .49 & .54 & .50 \\
\hline
\end{tabular}

${ }^{a}$ At $T 2$, number of respondents in the experimental and control condition using the combined criteria was 670 and 335 , respectively, and using the hours/week criteria the number was 933 and 442 , respectively.

${ }^{b}$ At T3, number of respondents in the experimental and control condition using the combined criteria was 815 and 367 , respectively, and using the hours/week criteria the number was 1,050 and 467 , respectively.

${ }^{c}$ Reemployed respondents were those working 20 or more hours per week and reporting they had already been working as many hours as they need. Unemployed respondents were those working less than 20 hours per week and/or reporting not working as many hours as they need.

${ }^{d}$ Reemployed respondents were those working 20 or more hours per week. Unemployed respondents were those working less than 20 hours per week or not working at all. 
67 , respectively) versus a difference of .08 for the high-risk group (.62 vs. .54 , respectively, Cohen's ES $h=.15$ ).

Next we analyzed the effects of the intervention on reported monthly income from paid work. Again, a general linear model ANOVA was performed with risk as a continuous variable and with repeated measures of monthly earnings from paid work at 2 and 6 months after the intervention. The means of monthly income are presented in Table IV by experimental condition and risk status. Not surprisingly, the most pronounced result is the effect of time. As more respondents became reemployed, the mean monthly income significantly increased from the 2-month to the 6-month posttest, $F(1,1208)=163.41, p<.01$. In addition, experimental condition had a significant main effect on monthly income, $F(1,1208)=3.89, p<$ .05 , as well as an interaction effect of condition by risk, $F(1,1208)=4.50$, $p<.05$, with high-risk respondents benefiting more from the intervention than their counterparts in the control group in both Time $2(d=.22)$ and Time $3(d=.26)$.

\section{Experimental Effects on Mental Health and Well-Being Outcomes}

Figure 3 presents the means of depressive symptomatology at time of screening and at the two posttests. To convey information on effect size, the means are expressed in standard deviation units.

As could be expected from the way risk status was constructed (being based primarily on the depression score), with no exception the mean depression score is consistently higher for the high-risk than for the low-risk

Table IV. Mean Monthly Income (Dollars) of Low- and High-Risk Respondents in the JOBS Experimental and Control Condition ${ }^{a}$

\begin{tabular}{|c|c|c|c|c|c|c|c|c|}
\hline \multirow[b]{3}{*}{ Risk status } & \multicolumn{4}{|c|}{ 2-Month posttest } & \multicolumn{4}{|c|}{ 6-Month posttest } \\
\hline & \multicolumn{2}{|c|}{ Experimental } & \multicolumn{2}{|c|}{ Control } & \multicolumn{2}{|c|}{ Experimental } & \multicolumn{2}{|c|}{ Control } \\
\hline & $M$ & $S D$ & $M$ & $S D$ & $M$ & $S D$ & $M$ & $S D$ \\
\hline Low & 733 & 1151 & 626 & 965 & 1147 & 1282 & 1192 & 1073 \\
\hline High & 720 & 996 & 513 & 860 & 1098 & 1134 & 828 & 973 \\
\hline
\end{tabular}

${ }^{a}$ Number of respondents in the low-risk and high-risk experimental condition was 511 and 313 , respectively, and in the control condition the number was 231 and 157, respectively, for a total of 1,212 . These numbers are the same for the 2 -month and the 6-month posttest. 
respondents (Table V). Furthermore, whereas at the time of screening, there was no difference in mean depression between the respondents in the experimental and the control group of the respective risk groups, at both 2-month and 6-month posttests, the high-risk respondents in the experimental group had lower depression scores than their high-risk counterparts in the control group. Thus, the Condition $\times$ Time and Condition $\times$ Risk interactions were statistically significant (both $p<.05$ ). Further analyses indicated that for the low-risk respondents, none of the differences between experimentals and controls were statistically significant. In contrast, and as expected for the high-risk respondents, there was no statistical difference at screening, $t(512)=1.38, p<.16$, but there was a statistically significant difference at 2-month and 6-month posttests, $t(512)$ $=2.02, d=.20$, and $t(512)=3.08, d=.22, p<.05$ and .01 , respectively. In summary, in both follow-up periods, only the high-risk respondents in the experimental group exhibited significantly lower levels of depressive symptomatology than their high-risk counterparts in the control group.

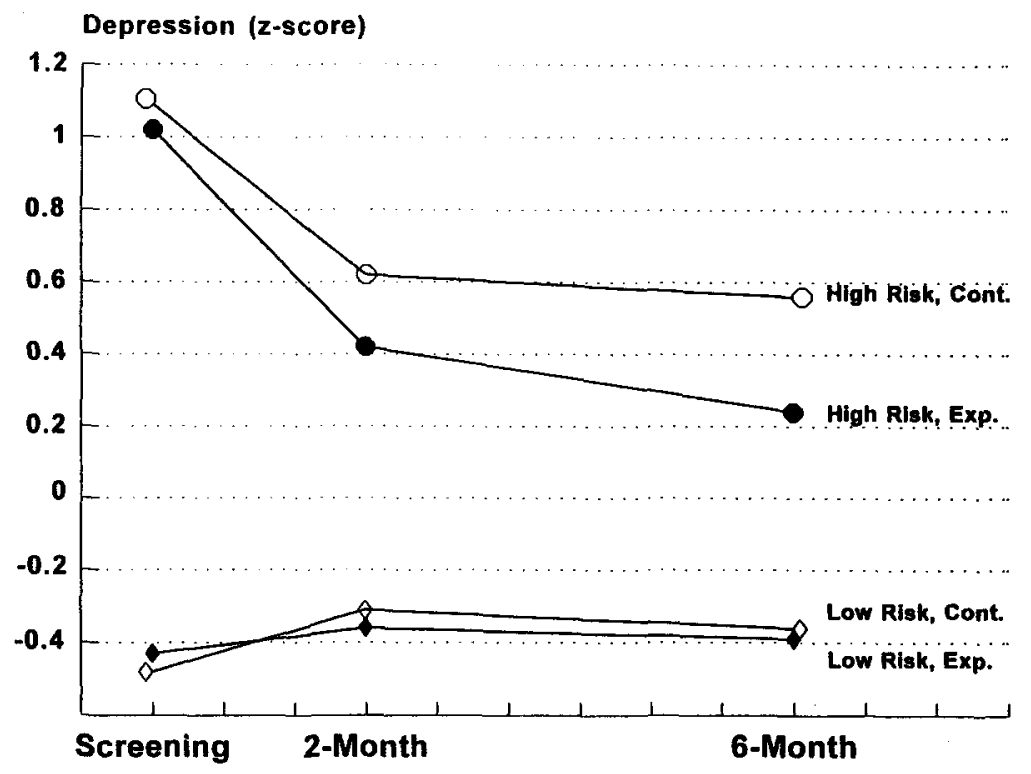

Fig. 3. Mean $z$ scores of depression symptoms for low- and high-risk respondents in the JOBS field experiment. 


\section{Convergent Validity of the Intervention Effects Based on the Reports of Both Job Seekers and Their Significant Others}

As shown in Table I, the intercorrelations among the various measures of mental health (i.e., depression, distress) and well-being (i.e., role and emotional functioning) within each type of respondent (i.e., focal respondents and significant others) are moderate to high, mostly above .5 . However, the intercorrelations between the respective measures based on the job seekers and those based on the significant others are somewhat lower, mostly about .4. These lower correlations raise the question of the extent to which the pattern of results shown with depression would replicate when the analyses are based simultaneously on the respective measures from both types of respondents.

To examine the question of the convergent validity of the effects of the intervention on mental health outcomes, we conducted multivariate analyses (MANOVAs) of two measures that were available from both the focal respondents and their significant others only at the 6-month posttest. For each measure, the spouse/significant other provided ratings of his or her observations of the focal respondent's behaviors, reactions and symptoms, who in turn, rated his or her own experiences using the same 5-point scales. The two MANOVAs included the measure of distress symptoms and of role and emotional functioning at Time 3 posttest. Table VI includes the results of the MANOVAs and Fig. 4 presents the means (in standard deviation units) of these measures.

The analyses produced a statistically significant Condition $\times$ Risk interaction effect for both distress $(p<.05)$ and functioning $(p<.01)$, as well as a Risk main effect for both measures $(p<.01)$, and a Condition main effect for distress $(p<.05)$. As can be seen in Figure 4, the analyses produced the same consistent pattern of statistically significant results. Additional results from the MANOVA analyses revealed that, while as noted above, the Condition $\times$ Risk interactions were statistically significant, the Rater (Focal Respondent vs. Significant Other) $\times$ Condition $\times$ Risk interactions were not statistically significant $(p<.28$, and .51 , respectively, for distress and functioning). The absence of the three-way interaction effects indicates that the pattern of Condition $\times$ Risk interaction was not different for both focal respondent and significant other data. There is virtually no difference in mean severity of distress symptoms or level of functioning between the low-risk status experimental and control group respondents ( $t$ $=0.21$ and 0.37 , respectively, for focal respondent distress and functioning, and $t=-1.09$ and 0.62 , respectively, for reports of significant other). In contrast, the high-risk respondents in the experimental group displayed lower levels of distress symptoms and better functioning than their coun- 
Table V. Summary Table of General Linear Model Procedure of ANOVA of Depression Symptoms

\begin{tabular}{lrcrr}
\hline \multicolumn{1}{c}{ Source } & $d f$ & $S S$ & $M S$ & \multicolumn{1}{c}{$F$} \\
\hline \multicolumn{4}{c}{ Between subjects } & \\
Condition (C) & 1 & 3.12 & 3.12 & $7.63^{b}$ \\
Risk & 1 & 475.72 & 475.71 & $1161.25^{b}$ \\
$\mathrm{R} \times \mathrm{C}$ & 1 & 1.68 & 1.68 & $4.10^{a}$ \\
Error & 1331 & 545.25 & 0.41 & \\
& & & & \\
Time (T) & 2 & 11.20 & 5.60 & $30.25^{b}$ \\
$\mathrm{~T} \times \mathrm{C}$ & 2 & 1.45 & 0.72 & $3.91^{a}$ \\
$\mathrm{~T} \times \mathrm{R}$ & 2 & 50.49 & 25.25 & $136.37^{b}$ \\
$\mathrm{~T} \times \mathrm{R} \times \mathrm{C}$ & 2 & 0.22 & 0.11 & 0.61 \\
Error (Time) & 2662 & 492.81 & 0.19 & \\
\hline
\end{tabular}

$$
\begin{aligned}
& a_{p}<.05 \\
& b_{p}<.01
\end{aligned}
$$

terparts in the control group $(t=2.78, d=.25$, and $t=-4.07, d=.32$, both $p<.01$, respectively, for focal respondent distress and functioning, and $t=2.20, d=.20$, and $t=-2.19, d=.17$, both $p<.05$, respectively, for reports of significant other).

\section{Actual Effects of Participation in the Intervention: Comparing Participants with their Control Group Counterparts}

In conducting the analyses presented above, we chose to preserve the integrity of randomization in the field experiment (Cook \& Campbell, 1979). Therefore, we included in the analyses all respondents who had been originally assigned to the experimental group, whether or not they were actually exposed to the JOBS Intervention Seminar. Since $46 \%$ of the experimental group respondents did not attend the JOBS intervention, the effects of the intervention and its interaction with risk status represent very conservative lower bound estimates of the true magnitude of the effects on actual participants. In terms of effect size $d$ (Cohen, 1988), the differences between the experimental and control conditions for the high-risk respondents ranged at Time 3 from .14 (for hours working per week) to .32 (for role and emotional functioning). 
Table VI. Summary Table of General Linear Model Procedure of MANOVA of Distress and of Functioning

\begin{tabular}{|c|c|c|c|c|}
\hline Source & $d f$ & $S S$ & $M S$ & $F$ \\
\hline \multicolumn{5}{|c|}{ Distress } \\
\hline Condition (C) & 1 & 2.37 & 2.37 & $4.24^{a}$ \\
\hline Risk (R) & 1 & 127.41 & 127.41 & $228.13^{b}$ \\
\hline $\mathbf{R} \times \mathbf{C}$ & 1 & 2.96 & 2.96 & $5.29^{a}$ \\
\hline Error & 1418 & 791.96 & 0.56 & \\
\hline \multicolumn{5}{|c|}{ Functioning } \\
\hline C & 1 & 1.90 & 1.90 & 3.38 \\
\hline $\mathbf{R}$ & 1 & 57.68 & 57.68 & $102.77^{b}$ \\
\hline $\mathbf{R} \times \mathbf{C}$ & 1 & 3.95 & 3.95 & $7.04^{b}$ \\
\hline Error (Time) & 1425 & 799.83 & 0.56 & \\
\hline
\end{tabular}

Departing from the above most conservative analyses, we proceeded to estimate the JOBS intervention effects on the actual participants by comparing them with their counterparts in the control group. These counterparts are defined as the "would-be participants," that is, the subgroup of persons from the control group who would become participants were they to be invited to the intervention. For this comparison we used an analytic strategy developed by Bloom (1984) and applied to our earlier JOBS I data (Vinokur, Price, \& Caplan, 1991). The estimation of the mean of the would-be participants is based on the plausible assumption, supported by the logic of randomization, that the control group consists of the same proportion of respondents who would, and others who would not, participate in the intervention as in the experimental group. Note that the known mean of the control group is composed of (equal to) the weighted contributions of the would-be participants and the would-be nonparticipants. The weights are the known proportions of participation (i.e., $p=$ .54 ) and nonparticipation (i.e., $1-p=.46$ ). Thus, to extract the desired estimated mean of the would-be participants from the mean of the total control group, we substitute the known mean of the subgroup of nonparticipants from the experimental group for the unknown mean of the would-be nonparticipants of the control group and solve the equation. (This 

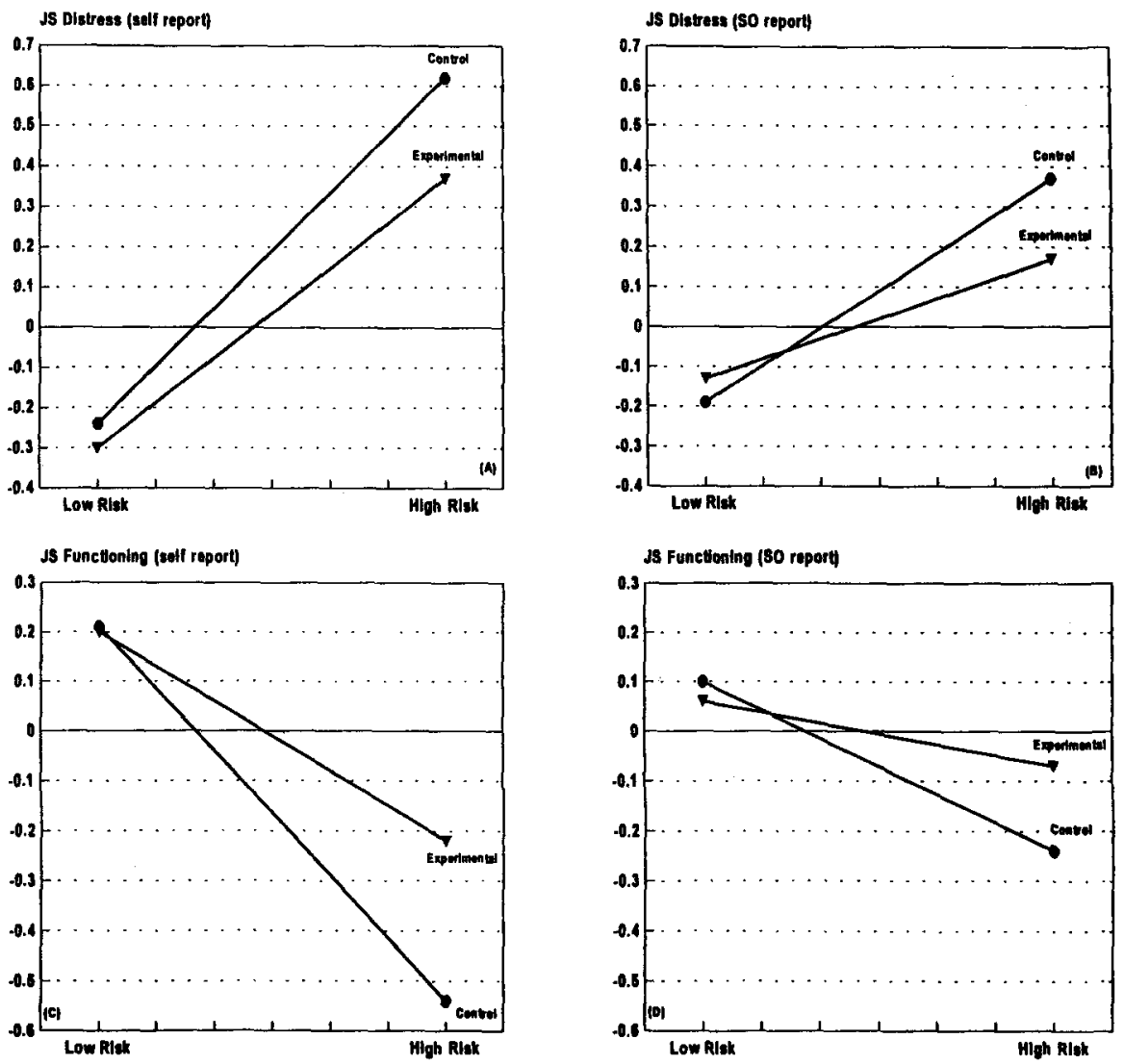

Fig. 4. Mean $z$ scores of job seeker's (JS) distress reported by job seeker (upper left-hand, Fig. A), and by his/her significant other (SO) (upper right-hand, Fig. B), and of job seeker's functioning reported by job seeker (lower left-hand, Fig. C), and by his/her significant other (lower right-hand, Fig. D) at 6-month follow-up.

substitution is justified on the ground that these are equivalent subgroups of persons who did not participate in the intervention.)

The application of this procedure to estimate the intervention's effects on the actual participants using all the outcomes that were examined in the full experimental analyses resulted in consistently large increases in the effect size over those produced using the full randomized groups. Without exception, we found that the estimated effects on the actual participants 
were nearly twice as large as those obtained using the full randomized design. ${ }^{7}$ Specifically, compared to the results obtained using the full design, which ranged in effect size from .14 (for hours of work per week) to .32 (for role and emotional functioning), the estimated effect size of participation ranged from .25 to .62 (respectively, for hours of work per week and for role and emotional functioning).

\section{DISCUSSION AND CONCLUSIONS}

Like its predecessor, the JOBS II intervention was designed to provide unemployed participants with social support, job search skills, and inoculation against setbacks as necessary components for enhancing their sense of mastery. Our results show that this proximal goal of the intervention was fully accomplished. That is, the findings demonstrate that the respondents in the intervention group had significantly higher levels of mastery than their control group counterparts. However, the analyses do not provide information on which one or more of these intervention components is responsible for the results. These components were intended to reinforce each other, and it may be that all are needed to produce the desired distal outcomes, which include both reemployment in high quality jobs and mental health.

The randomized JOBS II field experiment did, indeed, produce these desired outcomes. Our analyses replicated the findings of the earlier JOBS I study regarding the beneficial effects of the intervention on reemployment and mental health. More specifically, the JOBS II study replicated the results reported by Price et al. (1992) regarding the differential effects of the intervention on those identified retrospectively as low- and high-risk respondents. Using prospective screening to identify risk for depression, our results demonstrate that the JOBS II intervention had significant effects on mental health outcomes 2 and 6 months after the intervention for the high-risk respondents. Moreover, the results extend the earlier findings in showing that the beneficial effects of the intervention for high-risk respondents apply to reemployment as well as to mental health outcomes.

${ }^{7}$ To compute the effect size of participation one needs to estimate the joint standard deviation of the sample of participants and the would-be participants from the control group. We estimated this standard deviation by pooling the standard variations of the participants from the experimental group with the standard deviation of the entire control group. As indicated in our earlier work (Vinokur et al., 1991, see Footnote 5) and in others (Heaney, 1991), the standard deviations of the participants, the nonparticipants, and the control group are very similar, and therefore, any estimate based on these parameters is quite robust. 
Because the JOBS intervention also promotes reemployment, the issue of whether it merely promotes the reemployment of program participants at the expense of displacing other workers needs to be addressed. There is reason to believe that such displacement effects are minimal. Davidson and Woodbury (1993) have examined the issue of displacement effects of programs that are intended to promote the reemployment of workers who lost their job and qualify for unemployment compensation. They found that the displacement effects of the programs were minimal and were offset by overall improvement in the performance of the economy that results from reducing the duration of job vacancies. This acceleration of job-filling, in turn, leads to the creation of a greater number of job opportunities. Thus, if programs that promote faster reemployment succeed in reemploying people more quickly or in helping people obtain jobs more suitable for their skills, they enhance the efficiency of the labor market and ultimately, contribute to economic growth.

In summary, our analyses produced consistent findings indicating that although the intervention had practically no benefit for the low-risk participants, it benefited the high-risk participants who needed it most. Furthermore, these benefits were produced by an intervention that was significantly shorter in duration (over 1-week vs. 2-week period, and with $30 \%$ fewer meeting hours) than the original intervention. It is also worth noting that the replicated findings were produced at a time when the labor market conditions for job seekers were more difficult than those for the intervention participants in the earlier JOBS I study.

The fact that the intervention benefited only the high-risk respondents and that we have the means for screening and recruiting high-risk participants suggests that the efficacy of the intervention may be increased by providing it only to high-risk individuals. However, there is the possibility that while the low-risk participants do not benefit from the intervention, their participation in the various group processes throughout the intervention produces positive effects on the ability of the high-risk participants to benefit from the intervention. For example, by having higher self-esteem, confidence and social skills, the low-risk participants may promote effective and socially supportive interactions among group members and provide the necessary positive role models for the high-risk participants. Therefore, the exclusion of low-risk participants from the program could undermine the effectiveness of the intervention process. Accordingly, the merit of implementing the intervention exclusively for high-risk participants should not be taken for granted, but rather tested in future research.

A related caution should be exercised in designing future implementation efforts of the JOBS intervention. The caution relates to certain limitations of the external validity of our study. Two factors that limit the 
generalizability of the study stem from our decision to recruit respondents to the study from the state unemployment compensation offices and to restrict eligibility to those recently unemployed, that is, those who lost their job fewer than 14 weeks from time of recruitment. An additional unintended factor that limits generalizability stems from the significant dropout of younger respondents and those experiencing higher levels of financial strain. Future studies may investigate whether other demographically distinct subgroups such as the chronically unemployed and those experiencing economic hardship could benefit from the JOBS intervention, and whether modifications are needed to make the intervention effective for these particular groups.

The fact that the JOBS II intervention had significant effects on reemployment outcomes such as monthly income, as well as mental health outcomes, is of special significance. There is evidence that both outcomes have a reciprocal relationship, each one influencing the other over time. Hamilton et al. (1993) demonstrated that depression among auto workers experiencing layoffs contributed to prolonged unemployment. Other studies have shown that reemployment restored mental health to pre-unemployment levels through its effect on the reduction of economic hardship and financial strain (e.g., Kessler et al., 1988). As our current screening data and earlier risk analyses indicate, financial strain is a significant component of high risk for mental health problems among recent job losers. Furthermore, financial strain was found to be a mediator between unemployment status and poor mental health outcomes in earlier studies (Kessler, Turner, \& House, 1987, 1988) and is probably a critical mediator of negative mental health outcomes for other life events as well (Umberson, Wortman, \& Kessler, 1992).

We have restricted our use of data from spouses and significant others primarily to establishing the convergent validity of measures of distress and personal functioning. Indeed, we were able to show that the JOBS II intervention had positive effects on role and emotional functioning not only as reported by focal respondents but as also observed by spouses and significant others. These findings are encouraging since they triangulate intervention effects by obtaining additional reports by natural raters in the environment of the focal respondent. Our data present additional opportunities to understand the role of spouses and significant others in supporting or undermining the coping attempts of job losers. Other research indicates that job loss may affect family processes and the well-being of both spouses (Liem \& Liem, 1988; Penkower, Bromet, \& Dew, 1988) and children (Justice \& Duncan, 1977; Steinberg, Catalano, \& Dooley, 1981). But the influence of family dynamics may also flow in the other direction; spouses or significant others may play key roles in providing so- 
cial support or social undermining to job seekers, which, in turn, may affect their psychological well-being and the motivation for job search behavior. Thus, the dynamics of social support and social undermining and their role in affecting psychological well-being and the motivation for job search will be explored in subsequent analyses.

These results by themselves do not reveal the mechanisms by which the JOBS intervention has its effects. For example, the mechanisms by which JOBS II increases the likelihood of reemployment, remain unclear. As we indicated earlier, the theoretical rationale underlying the JOBS intervention aims at increasing participant motivation for job search as well as increasing job search skills. Indeed, our earlier research demonstrated that the intervention increased job search behavior (van Ryn \& Vinokur, 1992). However, how such increased motivation, the intensity of job search, or skills actually lead to improved reemployment and mental health outcomes remains to be discovered. A detailed analysis of the causal mechanisms leading from exposure to the JOBS intervention to an enhanced sense of mastery may illuminate the mechanisms by which this preventive intervention has its effects and represents still another avenue for future analyses.

\section{REFERENCES}

Bandura, A. (1977). Self-efficacy: Toward a unifying theory of behavior change. Psychological Review, 84, 191-215.

Barling, J. (1990). Employment, stress and family functioning. New York: Wiley.

Bentler, P. M. (1989). EOS Structural Equation Program Manual. Los Angeles: BMDP Statistical Software.

Bentler, P. M., \& Bonnett, D. G. (1980). Significance tests and goodness of fit in the analysis of covariance structures. Psychological Bulletin, 88, 588-606.

Blinder, A. S. (1987). Hard heads and soft hearts: Tough minded economics for a just society. Reading MA: Addison-Wesley.

Bloom, H. S. (1984). Accounting for no-shows in experimental evaluation designs. Evaluation Review, 8, 225-246.

Brown, C. H. (1991). Comparison of mediational selected strategies and sequential designs for preventive trials: Comments on a proposal by Pillow et al. American Joumal of Community Psychology, 19, 837-846.

Caplan, R. D. Abbey, A., Abramis, D. J., Andrews, F. M., Conway, T. L., \& French, J. R. P. (1984). Tranquilizer use and well-being: $A$ longindinal study of social and psychological effects (Technical Report Series). Ann Arbor: University of Michigan, Institute for Social Research.

Caplan, R. D., Vinokur, A. D., Price, R. H., \& van Ryn, M. (1989). Job seeking, reemployment, and mental health: A randomized field experiment in coping with job loss. Joumal of Applied Psychology, 74, 759-769.

Catalano, R. (1991). The health effects of economic insecurity. American Joumal of Public Health, 81, 1148-1152.

Catalano, R., \& Dooley, D. (1977). Economic predictor of depressed mood and stressful life events in a metropolitan community. Joumal of Health and Social Behavior, 18, 292-307. 
Chamberlain, N. W., Cullen, D. E., \& Lewin, D. (1980). The labor sector (3rd ed.). New York: McGraw-Hill.

Cobb, S., \& Kasl, S. V. (1977). Termination: The consequences of job loss (NIOSH Research Report, DHEW Publication No. 77-224). Washington, DC: U.S. Government Printing Office.

Cohen, J. (1988). Statistical power analysis for the behavioral sciences. (2nd ed.). Hillsdale, NJ: Erlbaum.

Cohen, J., \& Cohen, P. (1983). Applied multiple regression/correlational analysis for the behavioral sciences (2nd ed.). Hillsdale, NJ: Erlbaum.

Cook, T. D., \& Campbell, D. T. (1979). Quasi-experimentation: Design \& analysis issues for field settings. Boston: Houghton Mifflin.

Curran, J. (1992). JOBS: A manual for teaching people successful job search strategies. Ann Arbor: Michigan Prevention Research Center, Institute for Social Research.

Davidson, C., \& Woodbury, S. A. (1993). The displacement effect of reemployment bonus programs. Journal of Labor Economics, 11, 575-605.

Derogatis, L. R., Lipman, R. S., Rickles, K., Uhlenhuth, E. H., \& Covi, L., (1974). The Hopkins Symptom Checklist (HSCL). In P. Pichot (Ed.), Psychological measurements in psychopharmacology: Modem problems in pharmacopsychiatry (Vol. 7, pp. 79-110). New York: Karger, Basel.

Derogatis, L. R., \& Melisaratos, N. (1983). The brief symptom inventory: An introductory report. Psychological Medicine, 13, 595-605.

Dew, M. A., Bromet, E. J., \& Schulberg, H. C. (1987). A comparative analysis of two community stressors' long term, mental health effects. American Joumal of Community Psychology, 15, 167-184.

Eden, D., \& Aviram, A. (1993). Self-efficacy training to speed reemployment: Helping people to help themselves. Joumal of Applied Psychology, 78, 352-360.

Emery, R. E. (1991). Mediational screening in theory and in practice. American Joumal of Community Psychology, 19, 853-857.

Fryer, D., \& Payne, R. (1986). Being unemployed: A review of the literature on the psychological experience of unemployment. International Review of Industrial and Organizational Psychology (Chap. 8, pp. 235-278).

Galassi, J. P., Delo, J. S., Galassi, M. D., \& Bastien, S. (1974). The college self-expression scale: A measure of assertiveness. Behavior Therapy, 5, 165-171.

Gurin, P., Gurin, G., \& Morrison, B. M. (1978). Personal and ideological aspects of internal and external control. Social Psychology, 41, 275-296.

Hamilton, V. L., Hoffman, W. S., Broman, C. L., \& Rauma, D. (1993). Unemployment, distress, and coping: A panel study of autoworkers. Journal of Personality and Social Psychology, 65, 234-247.

Heaney, C. A. (1991). Enhancing social support at the workplace: Assessing the effects of the caregiver support program. Health Education Quarterly, 18, 477-494.

Hansen, W. B., Collins, L. M., Malotte, C. K, Johnson, C. A., \& Fielding, J. E. (1985). Attrition in prevention research. Joumal of Behavioral Medicine, 8, 261-275.

Hoelter, J. W. (1983). The analysis of covariance structures: Goodness-of-fit indices. Sociological Methods and Research, 11, 325-344.

Jones, W. H., \& Russell, D. (1982). The social reticence scale: An objective instrument to measure shyness. Joumal of Personality Assessment, 46, 629-631.

Justice, B., \& Duncan, D. F. (1977). Child abuse as a work-related problem. Corrective and Social Psychiatry, and Joumal of Behavior Technology. Methods and Therapy, 23, 53-55.

Kessler, R. C., Turner, J. B., \& House, J. S. (1987).Intervening processes in the relationship between unemployment and health, Psychological Medicine, 17, 949-961.

Kessler, R. C., Turner, J. B., \& House, J. S. (1988). The effects of unemployment on health in a community survey: Main, modifying, and mediating effects. Joumal of Social Issues, 44, 69-85.

Kessler, R. C., Turner, J. B., \& House, J. S. (1989). Unemployment, reemployment, and emotional functioning in a community sample. American Sociological Review, 54, 648-657. 
Liem, R., \& Liem, J. H. (1988). The psychological effects of unemployment on workers and their families. Joumal of Social Issues, 44, 87-105.

Lykken, D. T. (1968). Statistical significance in psychological research. Psychological Bulletin, 70, $151-159$.

Marshall, G. N., \& Lang, E. L. (1990). Optimism, self-mastery, and symptoms of depression in women professionals. Joumal of Personality and Social Psychology, 59, 132-139.

Neter, J., \& Wasserman, W. (1974). Applied linear statistical models: Regression, analysis of variance, and experimental designs. Homewood, IL: R. D. Irwin.

Nunnally, J. C. (1978). Psychometric theory. New York: McGraw-Hill.

Pearlin, L. I., \& Schooler, C. (1978). The structure of coping. Journal of Health and Social Behavior, 19, 2-21.

Pearlin, L. I., Menaghan, E. G., Lieberman, M. A., \& Mullen, J. T. (1981). The stress process. Joumal of Health and Social Behavior, 22, 337-356.

Penkower, L., Bromet, E., \& Dew, M. (1988). Husbands' layoff and wives' mental health: a prospective analysis. Archive of General Psychiatry, 45, 994-1000.

Pillow, D. R., Sandler, I. N., Braver, S. L., Wolchik, S. A., \& Gersten, J. C. (1991). Theory-based screening for prevention: Focusing on mediating processes in children of divorce. American Joumal of Community Psychology, 19, 809-836.

Price, R. H., van Ryn, M., \& Vinokur, A. D. (1992). Impact of preventive job search intervention on the likelihood of depression among the unemployed. Joumal of Health and Social Behavior, 33, 158-167.

Price, R. H., \& Vinokur, A. D. (in press). Michigan JOBS Program: Supporting career transitions in a time of organizational downsizing. In M. London (Ed.). Employee development and job creation: Human resource strategies for organizational growth. Guilford.

Rathus, S. A. (1973). A 30-item schedule for assessing assertive behavior. Behavior Therapy, 4, 398-406.

Reich, R. B. (1991). The work of nations: Preparing ourselves for 21st century capitalism (1st ed.). New York: A. A. Knopf.

Reid, J. B. (1991). Mediational screening as a model for prevention research. American Joumal of Community Psychology, 19, 867-872.

Rosenberg, M. (1965). Society and the adolescent self-image. Princeton, NJ: Princeton University Press.

Rotter, J. B. (1966). Generalized expectancies for internal versus external control of reinforcement. Psychological Monographs, 80(Whole No. 609).

Steinberg, L, Catalano, R., \& Dooley, D. (1981). Economic antecedents of child abuse and neglect. Child Development, 52, 975-985.

Umberson, D., Wortman, C. B., \& Kessler, R. C. (1992). Widowhood and depression: Explaining long-term gender difference in vulnerability. Joumal of Health and Social Behavior, 33, 10-24.

U.S. Bureau of Labor Statistics (1988, January). Employment and Earning (Vol. 35). Washington, DC: U.S. Government Printing Office.

U.S. Bureau of Labor Statistics (1992, January). Employment and Earning (Vol. 39). Washington, DC: U.S. Government Printing Office.

van Ryn, M., \& Vinokur, A. D. (1992). How did it work? An examination of the mechanisms through which a community intervention influenced job-search behavior among an unemployed sample. American Joumal of Community Psychology, 20, 577-599.

Vinokur, A., \& Caplan, R. D. (1987). Attitudes and social support: Determinants of job-seeking behavior and well-being among the unemployed. Journal of Applied Social Psychology 17, 1007-1024.

Vinokur, A., Caplan, R. D., \& Williams, C. C. (1987). Effects of recent and past stress on mental health: Coping with unemployment among Vietnam veterans and non-veterans. Joumal of Applied Social Psychology, 17, 708-728.

Vinokur, A. D., Price, R. H., \& Caplan, R. D. (1991). From field experiments to program implementation: Assessing the potential outcomes of an experimental intervention 
program for unemployed persons. American Joumal of Community Psychology, 19, 543-562.

Vinokur, A. D., van Ryn, M., Gramlich, E. M., \& Price, R. H. (1991). Long-term follow-up and benefit-cost analysis of the Jobs Project: A preventive intervention for the unemployed. Joumal of Applied Psychology, 76, 213-219.

Warr, P. B. (1983). Job loss, unemployment and psychological well-being. In V. Allen \& E. van de Vliert (Eds.), Role transitions. New York: Plenum Press.

White, R. W. (1959). Motivation reconsidered: The concept of competence. Psychological Review, 66, 297-333.

Yeaton, W. H., \& Sechrest, L. (1981). Critical dimensions in the choice and maintenance of successful treatments: Strength, integrity, and effectiveness. Journal of Consulting and Clinical Psychology, 49, 156-157. 